\title{
Elementos para inserir as questões ambientais em aulas de física: da prática baseada em temas à complexificação do conhecimento
}

\author{
Giselle Watanabe-Caramello ${ }^{1}$ \\ Roseline Beatriz Strieder ${ }^{2}$
}

Resumo: As questões ambientais têm conquistado espaço significativo nas diversas esferas que compõem a sociedade e, nas últimas décadas, ganharam destaque no âmbito do ensino básico. Nesse contexto, a formação de professores ganha espaço nas discussões que se estabelecem. Buscando contribuir para essas discussões, o presente artigo, a partir de práticas efetivas de sala de aula vivenciadas por licenciandos em Física, discute limites e potencialidades de se considerar, na elaboração e desenvolvimento de sequências temáticas ambientais, (i) a prática educativa baseada em temas e (ii) a complexificação do conhecimento, entendidas como relevantes para o desenvolvimento de propostas centradas em questões ambientais.

Palavras-chave: Educação ambiental. Complexidade. Abordagem temática.

\section{Elements to incorporate environmental issues into physics classes: from the practice based on themes to knowledge complexification}

\begin{abstract}
Environmental issues have become increasingly significant in many spheres of society and, in recent decades, have gained prominence in basic education. In this context, teacher training has gained space in the discussions that take place. In order to contribute to these discussions, the present paper, based on effective classroom practices experienced by undergraduates in Physics, discusses the limits and potentials of considering in the design and development of thematic environmental sequences (i) an education based on themes and (ii) knowledge complexification, seen as relevant to the development of proposals focusing on environmental issues.
\end{abstract}

Keywords: Environmental education. Complexity. Thematic approach.

1 Professora do Instituto Federal de Educação, Ciência e Tecnologia de São Paulo e doutoranda em Interunidades em Ensino de Ciências na USP. gisellewatanabe@if.usp.br

2 Professora da Universidade Católica de Brasília. roseline@if.usp.br 


\section{Introdução}

Nas últimas décadas as preocupações em torno das questões ambientais têm aumentado a ponto de essas questões passarem a fazer parte das agendas e discussões de muitos países e organizações mundiais. Isso se deve a uma série de fatores, entre os quais podemos destacar as evidências de degradação ambiental apresentadas nos relatórios publicados pelo Painel Intergovernamental sobre Mudanças Climáticas (IPCC) e as publicações alarmistas presentes na mídia. A partir disso, alguns esforços para mudar os hábitos e atitudes das pessoas perante o meio ambiente estão sendo empreendidos. Mas isso, na maioria dos casos, não se reverte em ações efetivas no dia a dia dos cidadãos comuns. Ou seja, apesar da facilidade em reconhecer os problemas ambientais, é difícil identificar suas causas e propor medidas para enfrentá-las (CARVALHO, 2000).

Uma hipótese para essa ausência de compreensão e comprometimento com as questões ambientais refere-se ao tratamento isolado dado ao assunto pelas diferentes esferas que compõem a sociedade (por exemplo, as esferas política, econômica e científica), o que acaba marginalizando a participação da população em geral, principalmente dos grupos menos favorecidos (HANNIGAN, 2009; LAYRARGUES, 2005; LEFF, 2009; LENZI, 2006). Além disso, as situações de incerteza impregnadas na sociedade atual, caracterizando a sociedade de risco (BECK, 1997), interferem no posicionamento dos indivíduos diante da problemática ambiental.

Para Beck (1997), os riscos presentes nas relações que se estabelecem nas mais diferentes esferas que compõem a sociedade não podem ser percebidos, previstos, calculados e compensados. Nesse sentido, os indivíduos apenas se limitam a lidar com tais riscos, e não a buscar soluções efetivas para os mesmos. Para buscar tais soluções, os cidadãos podem recorrer ao conhecimento, instrumentos e interpretações técnico-científicas, que, na maioria das vezes, "pertencem" a um estrato muito restrito da sociedade, o que limita as interações necessárias numa democracia. Com isso, promove-se um discurso distante das esferas sociais representativas, contribuindo para um debate com uma tônica tecnocrática e naturalista que se ocupa da descrição empírica dos riscos e negligencia as outras dimensões que lhe são inerentes e necessárias para solucionar os problemas (BECK apud LIMA, 2005).

Nesse contexto, o desenvolvimento de ações voltadas à preservação e ao uso sustentável dos recursos naturais pode ser alcançado por meio de uma educação preocupada com a formação de cidadãos capazes de se posicionar diante de uma sociedade de risco (BECK, 1997). Uma formação preocupada com essas questões vai ao encontro de uma educação ambiental que, como destacado por Jacobi (2005), deve buscar a construção de um embasamento que promova uma atitude crítica, uma compreensão complexa e a politização da problemática ambiental por parte dos alunos. Isso requer que a escola incorpore em seu currículo discussões que busquem o desenvolvimento de diferentes visões de mundo, considerando tanto a complexidade no âmbito social (aspectos sociais, políticos, econômicos e ambientais) 
quanto a complexidade no âmbito científico (aspectos das ciências naturais, humanas etc.).

Considerando esse panorama, torna-se importante a inserção de discussões sobre as questões ambientais no contexto da sala de aula, pois é o local em que a sociedade tem contato, de forma mais efetiva, com os conhecimentos sistematizados pelas diferentes esferas sociais. Tomando a escola como um espaço estratégico e privilegiado para promover discussões dessa natureza, alguns pesquisadores vêm desenvolvendo propostas ambientais na Educação Básica, a exemplo dos trabalhos de Bianchi e Melo (2009), Bonotto (2008), Campaner e Longhi (2007) e Watanabe-Caramello e Kawamura (2008). Bianchi e Melo (2009) relatam suas experiências ao propor aulas focadas em ações de intervenção com base em uma situação-problema levantada pelos alunos. Já Bonotto (2008) procura identificar as compreensões, reações e ações dos professores inseridas em discussões sobre a questão ambiental em meio ao modelo capitalista e consumista. Campaner e Longhi (2007) centram seu trabalho em ações de sala de aula e analisam mudanças na argumentação dos alunos quando tratam as questões ambientais no âmbito escolar. Por fim, Watanabe-Caramello e Kawamura (2008) discutem a inserção de temas ambientais no contexto das aulas de Física, procurando evidenciar elementos a serem considerados nessa perspectiva. De uma forma geral, esses trabalhos incorporam desde reflexões teóricas até relatos e análises de propostas didáticas e destacam a importância de inserir discussões sobre a temática ambiental nos cursos de formação de professores e nas salas de aula.

$\mathrm{Na}$ intenção de contribuir para o universo de pesquisas voltadas à educação ambiental, o presente artigo reflete sobre os limites e potencialidades para incorporar discussões voltadas às questões ambientais, considerando sua complexidade, nas aulas de Física do Ensino Médio.

\section{Pressupostos teóricos}

Entre as diversas perspectivas que podem ser seguidas para o desenvolvimento de intervenções escolares centradas em questões ambientais, destacam-se as propostas de Delizoicov, Angotti e Pernambuco (2002) e García (1998).

Delizoicov, Angotti e Pernambuco (2002) defendem uma abordagem na qual a organização dos conteúdos curriculares deve estar centrada em temas, a partir dos quais são selecionados os conceitos científicos. Essa abordagem é entendida como oposta à abordagem conceitual, comumente utilizada no contexto educacional brasileiro e cuja lógica de organização dos currículos é estruturada pelos conceitos científicos.

Para a definição dos temas a serem trabalhados e a sua articulação com conhecimentos científicos, os autores propõem a dinâmica da Investigação Temática, sistematizada a partir das ideias do educador Paulo Freire. Essa dinâmica, constituída por cinco etapas, sinaliza a importância do estabelecimento de vínculos com a realidade dos educandos. Na primeira etapa é feito o 
levantamento preliminar das condições locais em que vivem os alunos e seus familiares; na segunda, em função da análise dos dados apreendidos, é feita a escolha, pelos educadores/ pesquisadores, de situações que possam vir a ser os temas geradores; na terceira, denominada círculo de investigação temática, da qual participam também pais de alunos e outros representantes da comunidade, são definidos os temas; na quarta, se realiza a redução temática, que é a elaboração e planejamento do ensino, e na quinta etapa é realizado o desenvolvimento do planejamento em sala de aula.

Assim, de acordo com Delizoicov, Angotti e Pernambuco (2002), o conteúdo programático nasce dos próprios educandos, da sua relação com o mundo, e vai se transformando à medida que esse mundo é desvendado. Nessa perspectiva, o conhecimento escolar é, principalmente, instrumento de compreensão e ação sobre o mundo físico e social, que se torna o objeto de estudo.

Para García (1998), o conhecimento escolar também deve estar vinculado com aspectos mais amplos que envolvem, por exemplo, as relações com o meio e as implicações sociais. Ele entende esse conhecimento como influenciado pelos conhecimentos científico (produzido pela academia, passando pelo crivo de um grupo de pesquisadores) e cotidiano (saberes, muitas vezes complexos, que são produzidos nas relações que se estabelecem no meio - colegas, familiares etc.). Mais especificamente, um conhecimento cotidiano enriquecido pelas diferentes formas de conhecimento, como o científico, técnico etc., torna-se um conhecimento escolar. Para dar unidade ao conhecimento escolar enquanto conhecimento cotidiano enriquecido, ele enfatiza a importância do uso dos conhecimentos gerais, em especial dos conhecimentos metadisciplinares, que são capazes de trazer os problemas à realidade educativa.

Em síntese, para García (1998), compreender o mundo só é possível se houver a transição de uma forma simples a outra mais complexa do conhecimento. Isso aponta a necessidade de complexificar o conhecimento. $\mathrm{Na}$ perspectiva da complexidade, destacam-se Morin (2007, 2009), Prigogine (1988, 1996) e Prigogine e Stengers (1984). O primeiro, por pensar uma forma complexa de ver e lidar com o mundo; o segundo, por incorporar na ciência aspectos do não equilíbrio, elemento essencial para discutir a questão ambiental.

Para Morin (2007, 2009), lidar com um mundo onde as relações que se estabelecem são complexas requer um pensar também complexo. Isso significa romper com a linearidade e simplificação estabelecidas tanto no âmbito social quanto no científico. Assim, para o autor,

[...] diferentemente de um pensamento simplificador que identifica a lógica ao pensamento, o pensamento complexo a governa evitando a fragmentação e a desarticulação dos conhecimentos adquiridos. $\mathrm{O}$ pensamento complexo não é, porém, uma nova lógica. $\mathrm{O}$ pensamento complexo precisa da lógica aristotélica, mas, por sua vez, necessita transgredi-la (e isso porque ela é igualmente pensamento). Ao ser paradigmaticamente dialógico, o pensamento complexo põe em evidência outros modos de usar a lógica. Sem rejeitar a análise, a 
disjunção ou a redução (quando for necessária), o pensamento complexo rompe a ditadura do paradigma da simplificação. Pensar de forma complexa torna-se pertinente quando nos defrontamos (quase sempre) com a necessidade de articular, relacionar, contextualizar. Pensar de forma complexa é pertinente quando se tem necessidade de pensar. (MORIN, 2009, p. 38).

$\mathrm{Na}$ perspectiva de Prigogine e Stengers (1984), um olhar mais crítico para as questões que permeiam a sociedade requer repensar a forma de lidar e interpretar a natureza, o que, consequentemente, remete à reaproximação do homem com a ciência. Essa reaproximação significa pensar numa linguagem científica menos isolada e mais próxima de um diálogo com a realidade. Um primeiro passo para isso pode estar no reconhecimento de que a ciência não pode continuar tratando os problemas da realidade como independentes e isolados. Assim, na esfera científica, torna-se essencial que as questões ambientais estejam pautadas por uma ciência que evidencie e considere a auto-organização em sistemas abertos, as interrelações, a ordem e desordem e as situações de não equilíbrio.

Em síntese, as contribuições desses autores convergem para a necessidade de levar as questões complexas, que incluem os problemas ambientais, para as salas de aulas. Isso significa incorporar aspectos da complexidade tanto no âmbito científico quanto no social. No âmbito científico, as questões ambientais são tratadas por uma ciência longe do determinismo e próxima das situações de não equilíbrio, de caos. No âmbito social, são explicitadas as relações intrincadas que se estabelecem ao se tratar da problemática ambiental (aspectos econômicos, sociais, políticos etc.). Contemplar aspectos da complexidade nos dois âmbitos apresentados leva à necessidade de uma nova forma de ver e tratar tais situações, o que requer uma formação que considere o pensamento complexo. $\mathrm{Na}$ sala de aula, isso reflete na inserção de temas nos currículos escolares, pautados pelos pressupostos da abordagem temática.

Assim, a partir do que é discutido por esses autores, para inserir propostas centradas nas questões ambientais, entende-se ser necessário considerar, principalmente, dois pressupostos: (i) a prática educativa baseada em temas e (ii) a complexificação do conhecimento, no que se refere tanto aos aspectos sociais (que incluem os políticos, econômicos etc.) quanto ao científico.

A partir desses elementos, foram desenvolvidas, no Ensino Médio, algumas intervenções que buscam promover uma educação ambiental pelo viés da complexidade. No presente artigo essas intervenções serão analisadas com a intenção de verificar até que ponto é possível considerar, em práticas efetivas de sala aula, os elementos anteriormente apresentados. Com isso se pretende apontar limites e potencialidades para os cursos de formação de professores preocupados com esse tópico, ou seja, com a inserção das questões ambientais na educação básica. 


\section{Contexto da investigação e pressupostos metodológicos}

As intervenções, foco da presente investigação, foram desenvolvidas no âmbito de duas situações voltadas à inserção da questão ambiental em aulas de Física do Ensino Médio e a partir de uma parceria entre um instituto federal e escolas da rede pública, ambos localizados na cidade de São Paulo, Brasil.

A primeira situação refere-se a atividades desenvolvidas no Programa Institucional de Bolsa de Iniciação à Docência (PIBID) e contou com a participação de dois licenciandos do primeiro ano do curso de Física e um professor supervisor (em exercício na rede pública de ensino), além de 50 alunos do Ensino Médio. A segunda situação refere-se às atividades desenvolvidas no âmbito de uma disciplina de estágio supervisionado oferecida no último ano da graduação em Física e que envolveu 21 licenciandos, 20 professores supervisores em exercício na rede pública e particular de ensino e cerca de 400 alunos da educação básica.

De forma geral, o trabalho desenvolvido em ambas as situações consistiu na elaboração e implementação de propostas, por parte dos licenciandos, que abarcassem a discussão de algum tema ambiental. Esse trabalho foi dividido em quatro etapas: (i) discussão sobre os conceitos que envolvem a Física do meio ambiente, (ii) produção de sequências temáticas ambientais para o Ensino Médio, (iii) análise de referenciais que discutem a abordagem de temas nas aulas e (iv) reflexão sobre a implementação das propostas.

$\mathrm{Na}$ primeira etapa, (i) discussão sobre os conceitos que envolvem a Física do meio ambiente, os licenciandos refletem sobre algumas das contribuições e limitações da ciência determinista e reducionista para, então, perceber a necessidade de um outro olhar para tratar as questões reais, nas quais a complexidade de sistemas se faz necessária. Em outras palavras, ao discutirem o meio ambiente partindo de uma visão de ciência simplificadora (MORIN, 2007), os licenciandos podem perceber as possíveis inconsistências com os parâmetros apresentados (por exemplo, previsões do aumento de temperatura da Terra), o que leva à necessidade de discussões pautadas pelas situações de não equilíbrio (PRIGOGINE, 1996; WATANABE; KAWAMURA, 2010). Cabe destacar que essas discussões são breves e apenas servem como uma aproximação ao problema ambiental.

Na segunda etapa, (ii) produção de sequências temáticas ambientais para o Ensino Médio, os licenciandos propõem atividades para a sala de aula utilizando aspectos da ciência complexa discutidos na etapa anterior. Para tanto, são propostos três assuntos norteadores: poluição do ar, poluição da água e mudanças climáticas. A escolha desses temas está atrelada tanto ao interesse dos licenciandos quanto ao do professor da escola onde a proposta será desenvolvida. Vale ressaltar que nessa etapa os licenciados já têm contato com a escola onde vão implementar as propostas e já sabem, considerando o plano do professor, onde as mesmas serão inseridas no currículo de Física. Após escolherem o tema, os licenciandos socializam as suas propostas com os demais colegas, que têm a tarefa de contribuir criticamente para os ajustes finais. Com isso, todas as propostas levadas 
para a escola passam por um momento de reflexão coletiva, aspecto de suma importância no processo de formação inicial.

$\mathrm{Na}$ terceira etapa, (iii) análise de referenciais que discutem a abordagem de temas nas aulas, há uma discussão sobre alguns referenciais que tratam a abordagem temática e a complexidade nas ciências naturais e sociais, entre os quais se destacam Delizoicov, Angotti e Pernambuco (2002), García (1998), Jacobi (2005), Morin (2007, 2009), Prigogine (1988, 1996) e Prigogine e Stengers (1984). Procura-se, dessa forma, refletir sobre os parâmetros necessários para a inserção de temas nas aulas de Física, incluindo a dificuldade em tratar temas complexos no ensino básico.

Por fim, na quarta etapa, (iv) reflexão sobre a implementação das propostas, os licenciandos retornam da escola e relatam suas experiências para os demais colegas. Além disso, como forma de sistematização, eles elaboram um relatório individual em que refletem sobre suas experiências, vinculando-as com as discussões teóricas realizadas ao longo do curso. Eles também produzem um material didático para o aluno, considerando sua experiência em sala de aula enquanto estagiários (regência e observação).

O desenvolvimento dessas atividades permite aprofundar múltiplas questões, como, por exemplo, as dificuldades em promover uma postura crítica e reflexiva por parte dos alunos, as potencialidades e limites no que se refere às relações entre os alunos da educação básica e os supervisores, ou entre estes e os licenciandos etc. Contudo, no presente trabalho a investigação centra-se nos limites e possibilidades de considerar os elementos teóricos apontados anteriormente em práticas efetivas de sala de aula e que dizem respeito à: (i) prática educativa baseada em temas e (ii) complexificaşão do conhecimento.

Como destacado, em ambas as propostas os licenciandos elaboraram sequências temáticas ambientais, as desenvolveram em escolas de Ensino Médio e, por fim, elaboraram relatórios individuais. Dessa forma, a análise da presente investigação pauta-se por dados oriundos desses dois instrumentos - sequências temáticas ambientais e relatórios individuais elaborados pelos licenciandos. Numericamente, foram analisadas 8 sequências temáticas ambientais, já que as mesmas são elaboradas em equipe, e 22 relatórios individuais.

Esses dados foram analisados de acordo com a análise de conteúdo proposta por Bardin (1988). Seguindo essa metodologia, num primeiro momento fez-se uma leitura ampla dos relatórios e das sequências elaboradas e, em seguida, a partir de uma leitura mais detalhada, realizaram-se as operações de codificação, enumeração, classificação e agregação do material, em função das categorias preestabelecidas.

Nessa etapa, como forma de sistematizar o procedimento de análise, foram identificadas questões norteadoras para cada categoria preestabelecida, como apontado na Tabela 1. 
Tabela 1. Sistematização dos dados.

\begin{tabular}{|l|l|}
\hline Elementos teóricos & \multicolumn{1}{|c|}{ Questões norteadoras } \\
\hline $\begin{array}{l}\text { (i) Prática educativa baseada } \\
\text { em temas }\end{array}$ & $\begin{array}{l}\text { Os licenciandos e os professores se mostraram favoráveis ao } \\
\text { desenvolvimento de propostas centradas em temas? Quais as } \\
\text { possibilidades e os desafios encontrados? }\end{array}$ \\
\hline $\begin{array}{l}\text { (ii) Complexificação do } \\
\text { conhecimento }\end{array}$ & $\begin{array}{l}\text { As sequências temáticas elaboradas incorporam aspectos } \\
\text { (sistema dinâmico) da complexidade? Quais as possibilidades e } \\
\text { quais os desafios encontrados? }\end{array}$ \\
\hline
\end{tabular}

Assim, seguindo a proposta de Bardin (1988), busca-se nos relatórios e nas sequências elaborados pelos licenciandos dados que permitam responder às perguntas anteriormente apresentadas. Feito isso, passou-se à etapa de inferência e interpretação dos resultados obtidos, que será descrita a seguir. A identificação dos relatórios e das sequências elaboradas pelos licenciandos deu-se, respectivamente, pelo sistema alfanumérico R1, R2,.. Rn e S1, S2, .. Sn, resguardando-se a identidade dos mesmos.

\section{Resultados}

Segue a discussão dos resultados da presente investigação, divididos em duas partes, conforme as categorias estabelecidas: (i) A prática educativa baseada em temas e (ii) complexificação do conhecimento.

\section{(i) A prática educativa baseada em temas}

No que se refere à aceitação do trabalho com temas, destaca-se que os licenciandos se mostraram dispostos a trabalhar nessa perspectiva. Não houve questionamentos sobre as possibilidades de trabalho com outras perspectivas, como, por exemplo, o trabalho com projetos, ainda que esses licenciandos tivessem espaço para isso.

Em contrapartida, o mesmo não aconteceu com os professores supervisores. Nesse caso foi possível identificar três grupos de professores: (i) aceitam a proposta, (ii) aceitam com ressalvas e (iii) não aceitam.

No grupo (i), dos que aceitam a proposta sem questioná-la $(9 \%$ dos relatórios), existem dois argumentos completamente opostos, mas justificáveis. $\mathrm{O}$ primeiro deles baseia-se no relato de professores entusiastas e o segundo, no dos desapontados com o sistema de ensino. Estão relacionados a esse argumentos, respectivamente, $\mathrm{R} 8$ e R21.

Quando mostrei para a professora a proposta de aplicação para alunos, ela se mostrou bem interessada e apoiou a idéia. (R8).

Quando indagado sobre a possibilidade da realização da minha proposta, o mesmo [professor supervisor] se mostrou favorável, indiferente, eu acho que seria o termo mais apropriado. De qualquer forma ele me deu 'carta branca' para fazer o que e como quisesse. 
Este mesmo comportamento teve o diretor, vice-diretor e coordenadora. (R21).

A partir dessa abertura dos professores supervisores ao trabalho temático ambiental, parece viável incorporar uma mudança no currículo de Física, considerando discussões pautadas por temas e assuntos que possam ser complexificados. Isso não significa se distanciar dos conteúdos já tratados nas escolas, mas incorporá-los em uma discussão mais próxima da realidade dos alunos, tal como evidenciam Delizoicov, Angotti e Pernambuco (2002), ao considerarem os temas advindos da comunidade, e García (1998), ao dar importância aos assuntos do mesocosmo. No entanto, essa abertura dos professores supervisores é muito restrita. Os dados desta pesquisa revelam que a maioria deles está preocupada em cumprir os currículos estabelecidos, caracterizando a aceitação da proposta com ressalvas.

No grupo dos que aceitam a proposta com ressalvas ( $72 \%$ dos relatórios), nota-se a preocupação dos professores com diversos fatores, entre os quais se destacam, principalmente, a questão do tempo e o problema em cumprir o currículo estabelecido tanto pela escola, no caso dos colégios particulares, quanto pelo Estado. O trecho a seguir evidencia essa postura.

A princípio percebi que a base do planejamento era a proposta curricular do Estado de São Paulo, uma vez que seriam usadas as apostilas fornecidas pelo governo [...] diante da situação perguntei [à] professora qual seria o motivo desse tema (ambiental) não ser abordado, sua resposta foi que o número de aulas previsto era muito pequeno e não seria possível tratar os assuntos do currículo. (R11).

Ainda nesse grupo, a maioria dos professores cede as aulas com a ressalva de que os licenciandos as articulem ao conteúdo já trabalhado por eles. Nesse contexto, insere-se o excerto R3:

Depois de algumas alterações (do professor), o projeto acabou bastante modificado em relação à proposta inicial. Tomou um caráter mais conceitual e com exemplos que já haviam sido dados pelo professor. Segundo ele, isso foi necessário para que os alunos não dissessem que cada professor falava uma coisa diferente. (R3).

No grupo dos que não aceitam a proposta (19\%) aparece, novamente, a preocupação dos professores em manter o currículo da escola e em cumprir prazos. Mas, nesse caso, os professores nem se dispõem a discutir o assunto e não cedem espaço para os licenciandos estagiários, como destacado em R17 e R10.

No colégio no qual cumpri meu período de estágio, não foi possível realizar a atividade, pois eles utilizam material apostilado e seguem fielmente as datas previstas para cada aula, devido aos simulados e provas determinados no início de cada bimestre. (R17). 
[...] conversamos com o professor e, apesar da matéria estar sendo proposta na apostila do Estado [adotada nessa escola], ele não acha importante esse assunto. Além disso, esse conteúdo está no final da apostila e, segundo o professor, fica difícil passá-lo devido ao tempo. (R10).

A partir desses resultados, destaca-se a importância da inserção do tema ambiental na sala de aula considerando os currículos já estabelecidos nas escolas. Apenas 9\% dos professores aceitaram o desenvolvimento do trabalho com temas sem questionar, $72 \%$ aceitaram somente se fossem estabelecidos vínculos com o currículo estabelecido e 19\% não aceitaram, principalmente devido à ausência desses vínculos.

É importante destacar que não se defende a manutenção do currículo "tradicional", pois a proposta da abordagem temática vem justamente romper com essa lógica, que organiza os currículos escolares tomando como referência os conceitos científicos. O que se defende é considerar esses currículos ao organizarse a proposta. A justificativa está na viabilidade imediata da inserção do tema ambiental nas escolas, pois a necessidade de refletir e se posicionar diante das questões ambientais não pode ficar à mercê de uma futura e desejada mudança na educação.

Nessa linha, vale ressaltar a proposta de Watanabe-Caramello e Kawamura (2008), que incorpora o que as autoras evidenciam como organizações temática e conceitual. Essas organizações tratam de separar e identificar aspectos gerais e conceitos relacionados ao tema a serem abordados nas salas de aula, de modo que as escolhas ficam nas mãos dos professores. Essa proposta dá liberdade para que a escola possa tratar questões mais próximas de sua realidade, já que inclui um mapa geral dos assuntos ambientais e outro dos conteúdos vinculados ao tema e, além disso, possibilita a manutenção dos currículos estabelecidos na escola, como defendido no presente trabalho.

Assim, uma alternativa viável seria a inserção pontual de temas ambientais no currículo de Física, ou seja, a discussão de temas/assuntos que não fazem parte do currículo usual, mas que estão associados a ele e que podem ser compreendidos como complementares ou paralelos. Essa modalidade de intervenção vem sendo denominada por "enxerto" e amplamente utilizada em propostas vinculadas ao enfoque Ciência-Tecnologia-Sociedade (CTS) (GARCÍA; CEREZO; LÓPEZ, 1996).

Ao propor essa dinâmica para a inserção dos temas, o foco está na escola e no professor que vive a realidade da educação brasileira, que muitas vezes não tem tempo nem espaço necessários para mudar a organização na qual se encontra. Trabalhar com enxertos, considerando o currículo já estabelecido, facilita a inserção dos temas ambientais na escola, pois não muda completamente o planejamento que o professor vem seguindo, muitas vezes há longa data. Além disso, é necessário lembrar que os professores, em sua grande maioria, foram formados numa estrutura rígida em que havia um currículo mínimo e 
preestabelecido a ser cumprido, o que dificulta, muitas vezes, um olhar consonante com a proposta da abordagem temática.

Como destacado por Delizoicov, Angotti e Pernambuco (2002), pensar os currículos das diferentes disciplinas na perspectiva da abordagem temática constitui um desafio, pois representa uma ruptura com uma lógica já estabelecida há longa data. Nesse sentido, destaca-se a importância de inserir discussões sobre a nos cursos de formação de professores, pois, como apontado anteriormente, os licenciandos que tiveram a oportunidade de estudar o assunto se mostraram favoráveis ao trabalho com temas, o que não ocorreu com os professores, que não aprofundaram ou não tiveram contato com os pressupostos da abordagem temática durante sua formação.

A indicação de inserir discussões sobre a abordagem temática em cursos de formação de professores também é levantada por Coelho e Marques (2007), Forgiarini e Auler (2009), Lindemann et al. (2009) e Strieder, Watanabe-Caramello e Gehlen (2010), que analisam compreensões de professores sobre esse assunto e apontam que as mesmas se configuram como obstáculos para o desenvolvimento de abordagens temáticas, principalmente porque muitos não reconhecem os temas como um problema social, mas como uma forma de abordar conceitos científicos, e porque muitos assumem o papel de meros repassadores e reprodutores das informações veiculadas pela mídia, alimentando mitos e promessas em relação aos temas.

No que se refere a práticas de inserção dessas questões em cursos de formação inicial de professores, destaca-se o trabalho "Abordagem temática na formação de professores de Física", de Watanabe-Caramello, Strieder e Gehlen (2011), o qual, após analisar três disciplinas desenvolvidas com licenciandos em Física e voltadas à promoção e inserção de temas nas aulas de Física do Ensino Médio, aponta que os licenciandos que cursaram as disciplinas e tiveram a oportunidade de refletir sobre a questão mostraram um olhar diferenciado (em comparação com os professores) sobre a articulação de temas com a realidade dos alunos e sobre a articulação entre temas e os conteúdos de Física.

Assim, em síntese, no que se refere à prática educativa baseada em temas, os resultados indicam a importância de discutir seus pressupostos com os professores para que eles superem compreensões equivocadas sobre essa perspectiva. Além disso, como alternativa para iniciar a inserção das questões ambientais na Educação Básica, entende-se que é necessário considerar os currículos estabelecidos, desenvolvendo propostas pontuais.

\section{(ii) Complexificação do conbecimento}

Outro elemento investigado foi a incorporação da complexidade nas sequências temáticas ambientais levadas para as salas de aula pelos licenciandos. Incorporar os temas ambientais pelo viés da complexidade, nesse contexto, significa tratar os sistemas dinâmicos, tais como os sistemas naturais, com um olhar menos reducionista. Esse tratamento requer que as ênfases dinâmica, entrópica, temporal, das inter-relações e níveis hierárquicos (WATANABE- 
CARAMELLO; KAWAMURA, 2009) ganhem espaço nas discussões sobre meio ambiente. No entanto, para este artigo analisa-se apenas a ênfase dinâmica, ou seja, enfatizam-se os aspectos dinâmicos da natureza enquanto elemento que contribui para uma visão complexa.

A partir da análise das sequências temáticas, foi possível perceber que os licenciandos procuraram incorporar aspectos da complexidade em suas propostas; no entanto, na maioria das vezes (67\% das sequências temáticas ambientais), o fechamento das discussões tomava o rumo dos discursos reducionistas e deterministas. Nesses casos, as discussões sobre a dinâmica terrestre, que constituem elementos-chave para se explorar a questão ambiental, foram pouco contempladas. A preocupação estava em levantar informações e dados.

Por outro lado, isso não resultou em discussões ausentes de conceitos científicos, já que todas as sequências tiveram a preocupação em inserir a Física nas discussões ambientais. Nesse grupo encontram-se as sequências S9, S6, S7, S8 e $\mathrm{S} 3$, que vincularam às suas sequências temáticas ambientais os assuntos:

Variações de temperatura; camada atmosférica; fonte de energia; radiação eletromagnética; balanço radioativo; efeito estufa e troca de calor. (S9).

Poluição do ar; camada atmosférica; poluentes; composição do ar; fontes de poluição; instrumentos de medida; efeitos na saúde. (S8).

Poluentes; dinâmica dos ventos; inversão térmica; danos à saúde. (S6).

Energia; características da água; refração; ciclo das águas; agentes poluidores da água; tratamento e reciclagem da água. (S7).

As causas do aquecimento global (queima de combustíveis fosseis, queimadas e desmatamento, crescimento de grandes metrópoles etc.). (S3).

Nessas propostas, pode-se notar que a escolha dos conceitos científicos para tratar o tema ambiental está fortemente vinculada aos conteúdos presentes nos livros didáticos do Ensino Médio e submetida às orientações dos professores supervisores. Tais conceitos vinculam-se ao ano no qual o tema ambiental foi inserido. Nesse sentido, contemplou-se, na grande maioria, a Conservação de Energia no $1^{\circ}$ ano, a Termodinâmica no $2^{\circ}$ ano e aspectos da radiação (radiação eletromagnética) no $3^{\circ}$ ano. Esses assuntos aparecem como uma porta de entrada para as discussões que vão introduzir aspectos da dinâmica terrestre, ou seja, da complexidade.

Considerando todas as sequências temáticas ambientais, apenas 33\% delas incorporaram efetivamente em seus discursos aspectos da complexidade, tomando como referência a dinâmica terrestre, a exemplo dos trabalhos de S1, S2 e S5, apresentados a seguir.

Sistemas; equilíbrio térmico; consequências do desequilíbrio do efeito estufa; entropia; transferência de calor; fluxos de energia pelo planeta; importância do efeito estufa. (S1). 
Sistema em equilíbrio dinâmico; temperatura global média; ciclos do carbono e da água; efeito estufa. (S2).

Composição do ar, tipos de poluentes, danos à saúde, dinâmica de dispersão dos poluentes - da cidade para o interior; dados de emissão no mundo; relação da poluição com o efeito estufa - dinâmica terrestre; aumento da Temperatura. (S5).

(1) discussão crítica sobre o documentário "Uma verdade inconveniente" - Al Gore; (2) aula dialógico-expositiva sobre balanço radioativo Terra/ Sol e dinâmica da camada da atmosfera; (3) aula dialógico-expositiva sobre poluentes e métodos de medição da poluição atmosférica; (4) e (5) discussão sobre as visões cética e ortodoxa do aquecimento global. (S9).

Nessas sequências é possível perceber a preocupação com assuntos de natureza menos determinista, como o conceito de equilíbrio dinâmico e fluxos de energia, além do vínculo com questões sociais, econômicas e políticas, como a dispersão de poluentes nas cidades do interior, a emissão de gases no mundo e visões cética e ortodoxa sobre o aquecimento global.

A incorporação da complexidade nessas sequências temáticas, ainda que timidamente, aponta uma abertura, tanto dos licenciandos quanto dos professores supervisores, no que se refere à forma de lidar com a problemática ambiental no âmbito escolar. A complexidade nesse contexto refere-se a um sistema composto por muitas variáveis que no âmbito científico indica a necessidade de incorporar uma nova linguagem de ciência (MORIN, 2002; PRIGOGINE, 1988) e no âmbito social refere-se a um olhar mais atento às relações intrínsecas e de riscos que se estabelecem no sistema de sociedade atual (BECK, 1997; JACOBI, 2005).

Tal como anunciam Morin (2007) e Prigogine (1996), o tratamento das questões ambientais pautado pelos modelos simplificadores não dá margem para que os indivíduos reflitam sobre os problemas reais. Por outro lado, tal como se evidenciou nas sequências temáticas, ainda que não seja adequada para tratar as questões longe do equilíbrio, essa simplificação pode se tornar um caminho para a inserção da complexidade nos discursos escolares.

Vale lembrar que a crítica não está sendo feita à linguagem determinista, tão necessária ao desenvolvimento científico e tecnológico, mas à limitação que ela pode proporcionar quando a questão central está na dinâmica dos processos. $\mathrm{O}$ indivíduo que compreende as explicações dos fenômenos ambientais pelo viés da complexidade pode ter clareza sobre dois aspectos fundamentais: a dificuldade de estabelecer explicações fechadas para a questão ambiental e a necessidade de contar com as contribuições de outras esferas (social, política, econômica etc.) que compõem a sociedade.

Nesse contexto, parece essencial levar para as salas de aula questões que incorporem discussões de natureza temporal, dinâmica, sistêmica, entre outras, tal como evidenciado por García (1998), ao sistematizar os conceitos metadisciplinares, e por Watanabe-Caramello e Kawamura (2009), ao identificarem algumas de suas ênfases. Isso significa, por exemplo, tratar as questões relacionadas à problemática da poluição do ar numa perspectiva que evidencie as características regionais ou 
mundiais, assim como discutir a disponibilidade e as reações (dinâmica da atmosfera, incluindo os poluentes oriundos de ações antropogênicas) num ciclo dinâmico (ênfases temporal e dinâmica).

A partir dessas reflexões, nota-se a dificuldade de incorporar discussões ambientais pelo viés da complexidade, já que somente cerca de um terço dos licenciandos obteve êxito. Cabe ressaltar que, mesmo discutindo a complexidade dos sistemas, foram notórias as limitações dos licenciandos ao propor sequências temáticas pautadas pela dinâmica dos sistemas e pelo não equilíbrio. Esse aspecto pode estar relacionado tanto ao curto espaço dedicado ao assunto nos cursos de formação de professores quanto à dificuldade de se estabelecer uma linguagem de ciência ainda em pleno desenvolvimento, como é o caso da complexidade.

Um caminho para suprir essas 'deficiências' está na discussão da complexidade nos cursos de formação de professores. Essas discussões não devem ser pontuais, devem estar distribuídas ao longo dos cursos de licenciatura. Além disso, identificou-se que uma das portas de entrada para a complexidade pode ser a Termodinâmica (WATANABE-CARAMELLO; KAWAMURA, 2010), tal como também evidenciaram os próprios licenciandos nas propostas elaboradas. Isso contribui para que, por um lado, os professores possam explicitar a importância de um olhar simplificador que contribuiu para o avanço científico e, por outro, evidenciar a aproximação da ciência à realidade vivencial, ou seja, dos processos dinâmicos vivenciados diariamente pelos alunos.

\section{Considerações finais}

Referenciais teóricos utilizados neste trabalho (DELIZOICOV; ANGOTTI; PERNAMBUCO, 2002; GARCÍA, 1998) para balizar a inserção de questões ambientais na escola defendem o desenvolvimento de temas, mais especificamente, uma reorganização curricular. Contudo, na prática efetiva de sala de aula, propor e desenvolver um currículo centrado em temas se mostrou tarefa difícil e um grande limitador para a discussão de questões ambientais na escola por parte dos professores. Nesse sentido, uma vez que os principais conteúdos do currículo tradicional devem ser considerados, defende-se que algumas inserções e exclusões de conceitos no currículo preestabelecido devam ser realizadas a fim de que o professor encontre um caminho gradual para inserir temas ambientais. É importante destacar que não defendemos a manutenção de um currículo rígido que tome como referência somente os conceitos científicos.

Por outro lado e como forma de superar essa limitação, destaca-se a necessidade de inserir discussões sobre a abordagem temática nos cursos de formação de professores. Como apontam os resultados, essa inserção pode contribuir para uma efetiva implementação dos pressupostos da abordagem temática, ou seja, da organização do currículo escolar com base em temas, a partir dos quais são selecionados os conceitos científicos.

$\mathrm{Na}$ perspectiva defendida no presente trabalho, a abordagem dos temas ambientais precisa vir articulada a discussões sobre as dinâmicas do planeta e sobre as incertezas intrínsecas à questão, o que remete à necessidade de um olhar 
permeado pela complexidade. O entendimento da complexidade dos sistemas naturais (complexidade científica) pode contribuir para que os indivíduos tomem a problemática ambiental para si. Isso significaria, no âmbito escolar, mudar o tratamento dado às questões ambientais, que atualmente está baseado numa ciência simplificadora. No que se refere à complexidade no âmbito social, acreditamos que a problemática ambiental requer um olhar mais amplo que conte com as contribuições advindas das diferentes esferas (ciências sociais, filosóficas, econômicas etc.).

Desse modo, as discussões sobre a questão ambiental devem estar preocupadas em elucidar as relações envolvidas, e não os resultados negativos herdados da geração passada (poluições, degradação etc.). Essa abordagem pode contribuir para que as pessoas compreendam que atitudes localizadas podem influenciar o ciclo natural do planeta e repensem suas posturas, se responsabilizando pelas suas ações. Além disso, esse distanciamento das certezas promove um posicionamento crítico e reflexivo, defendido por Jacobi (2005), coerente com a sociedade de risco (BECK, 1997).

Por fim, destaca-se a importância de inserir discussões sobre a complexidade nos cursos de formação de professores. Como apontam os resultados, essa inserção pode contribuir para que futuros professores tenham clareza ao discutirem problemas relacionados ao meio ambiente, longe das determinações científicas.

\section{Referências}

BARDIN, Laurence. Análise de conteúdo. Lisboa: Edições 70, 1988.

BECK, Ulrich. A reinvensão da politica: rumo a uma teoria da modernização reflexiva. In: BECK, Ulrich; GIDDENS, Anthony; LASH, Scott (Org.). Modernizaçãa reflexiva. São Paulo: Unesp, 1997. p. 11-72.

BIANCHI, Cristina dos Santos; MELO, Waisenhowerk Vieira de. Desenvolvimento de um projeto de ação pedagógica para conscientização ambiental com alunos de $9^{\circ}$ ano do Ensino Fundamental. Revista Electrónica de Enseñanza de las Ciencias, v. 8, n. 3, p. 976-1003, 2009.

BONOTTO, Dalva Maria Bianchini. Educação Ambiental e Educação em Valores em um programa de formação docente. Revista Electrónica de Enseñanza de las Ciencias, v. 7, n. 2, p. 313-336, 2008.

BRASIL. Secretaria de Educação Média e Tecnológica. PCN+ Ensino Médio: Orientações Educacionais Complementares aos Parâmetros Curriculares Nacionais. Brasília: SEMTEC - MEC, 2002.

CAMPANER; Gertrudis; LONGHI; Ana Lía De. La argumentación en Educación Ambiental. Una estrategia didáctica para la escuela media. Revista Electrónica de Enseñanza de las Ciencias, v. 6, n. 2, p. 442-456, 2007. 
CARVALHO, Luiz Marcelo de. Educação Ambiental e a formação de professores. Brasília: Coordenação Geral de Educação Ambiental (COEA - MEC), 2000.

COELHO, Juliana Cardoso; MARQUES, Carlos Alberto. A chuva ácida na perspectiva de tema social: um estudo com professores de Química. Química Nova na Escola, São Paulo, n. 25, p. 14-19, 2007.

DELIZOICOV, Demétrio; ANGOTTI, José André; PERNAMBUCO, Marta Maria. Ensino de Ciências: fundamentos e métodos. São Paulo: Cortez, 2002.

FORGIARINI, Marcia Soares; AULER, Décio. A abordagem de temas polêmicos na educação de jovens e adultos: o caso do "florestamento" no Rio Grande do Sul. Revista Electrónica de Enseñanza de las Ciencias, v. 8, n. 2, p. 399-421, 2009.

FREIRE, Paulo. Pedagogia do Oprimido. 17. ed. Rio de Janeiro: Paz e Terra, 1987.

GARCÍA, José Eduardo. Hacia una teoría alternativa sobre los contenidos escolares. Sevilla, España: Díada, 1998.

GARCÍA, Marta I. González; CEREZO, José; LÓPEZ, José Luis. Ciencia, tecnología y sociedad. Una introducción al estudio social de la ciencia y la tecnología. Madrid: Tecnos, 1996.

GUIMARÃES, Mauro. Educação Ambiental Crítica In: LAYRARGUES, Philippe Pomier (Coord.). Identidades da educação ambiental brasileira. Brasília: Ministério do Meio Ambiente, 2004. p. 25-34.

HANNIGAN, John. Sociologia Ambiental. Petrópolis: Vozes, 2009.

JACOBI, Pedro Roberto. Educação Ambiental: o desafio da construção de um pensamento crítico, complexo e reflexivo. Revista Educaşão e Pesquisa, São Paulo, v. 31, n. 2, p. 233-250, 2005.

KRASILCHIK, Myriam. O professor e o currículo das ciências. São Paulo: EPU, 1987.

LAYRARGUES, Philippe Pomier. O cinismo da reciclagem: o significado ideológico da reciclagem da lata de alumínio e suas implicações para a educação ambiental. In: LOUREIRO, Carlos Frederico Bernardo, LAYRARGUES, Philippe Pomier; CASTRO, Ronaldo Souza de (Org.). Educação ambiental: repensando o espaço da cidadania. São Paulo: Cortez, 2005. p. 179-219.

LEFF, Enrique. Saber ambiental: sustentabilidade, racionalidade, complexidade, poder. Petrópolis: Vozes, 2009.

LENZI, Cristiano Luis. Sociologia Ambiental: risco e sustentabilidade na modernidade. Bauru: EDUSC, 2006.

LIMA, Gustavo Ferreira da Costa. Crise ambiental, educação e cidadania: os desafios da sustentabilidade emancipatória. In: LOUREIRO, Carlos Frederico Bernardo, LAYRARGUES, Philippe Pomier; CASTRO, Ronaldo Souza de (Org.). Educação ambiental: repensando o espaço da cidadania. São Paulo: Cortez, 2005. p. 109-141.

LINDEMANN, Renata Hernandez; MUENCHEN, Cristiane; GONÇALVES, Fábio Peres; GEHLEN, Simoni Tormöhlen. Biocombustíveis e o ensino de Ciências: compreensões de professores que fazem pesquisa na escola. Revista Electrónica de Enseñanza de las Ciencias, v. 8, n. 1, p. 342-358, 2009. 
MORIN, Edgar. Educar na era planetária: o pensamento complexo como método de aprendizagem no erro e na incerteza humana. São Paulo: Cortez; Brasília, DF: UNESCO, 2009.

. Introdução ao pensamento complexo. 3. ed. Porto Alegre: Sulina, 2007.

PRIGOGINE, Ilya. O nascimento do tempo. Rio de Janeiro: Edições 70, 1988.

. O fim das certezas: tempo, caos e as leis da natureza. São Paulo: Unesp, 1996.

PRIGOGINE, Ilya; STENGERS, Isabelle. A nova aliança. Brasília: Universidade de Brasília, 1984.

STRIEDER, Roseline Beatriz. Abordagem CTS e Ensino Médio: Espaços de Articulação. 2008. 236 f. Dissertação (Mestrado em Ensino de Ciências) - Universidade de São Paulo, São Paulo, 2008.

STRIEDER, Roseline Beatriz; WATANABE-CARAMELLO, Giselle; GEHLEN, Simoni Tormöhlen. Abordagem de temas no ensino médio: compreensões de professores de física. In: ENCONTRO DE PESQUISA EM ENSINO DE FÍSICA, 12., 2010, Águas de Lindóia. Disponível em: <http://www.sbf1.sbfisica.org.br/eventos/epef/xii/sys/ resumos/T0117-1.pdf >. Acesso em: 10 dez. 2010.

WATANABE-CARAMELLO, Giselle. Elementos para uma abordagem temática: a questão das águas e sua complexidade. 2008. 198 f. Dissertação (Mestrado em Ensino de Ciências) Universidade de São Paulo, São Paulo, 2008.

WATANABE-CARAMELLO, Giselle; KAWAMURA, Maria Regina Dubeux. Questões ambientais: em busca de perspectivas para a compreensão da complexidade. Revista Electrónica de Enseñanza de las Ciencias, Barcelona, v. extra, p. 3126-3129, 2009.

WATANABE-CARAMELLO, Giselle; KAWAMURA, Maria Regina Dubeux. Uma abordagem termodinâmica para discutir a física do meio ambiente. In: ENCONTRO DE PESQUISA EM ENSINO DE FÍSICA, 12., 2010, Águas de Lindóia. Disponível em: <http://www.sbf1.sbfisica.org.br/eventos/epef/xii/sys/resumos/T0173-1.pdf>. Acesso em: 10 dez. 2010.

WATANABE-CARAMELLO, Giselle; STRIEDER, Roseline Beatriz; GEHLEN, Simoni Tormöhlen. Abordagem temática na formação de professores de Física. In: SIMPÓSIO NACIONAL DE ENSINO DE FÍSICA, 19., 2011, Manaus. Disponível em: <http://www.sbf1.sbfisica.org.br/eventos/snef/xix/sys/resumos/T0142-1.pdf>. Acesso em: 25 mar. 2011.

\section{Artigo recebido em 13/2/2011 e aprovado em 14/9/2011.}

